\title{
Local Structure and Magnetic Characteristics of FINEMET Alloys Substituted by Vanadium
}

\author{
K. Brzózka, T. Szumiata, M. Gawroński, B. Górka \\ Department of Physics, Technical University of Radom \\ Krasickiego 54, 26-600 Radom, Poland \\ P. SovÁk, G. PAvlík And V. Kolesár \\ Institute of Physics, P. J. Šafárik University \\ Park Angelinum 9, 04154 Košice, Slovakia
}

\begin{abstract}
Amorphous and nanocrystalline FINEMET-type alloys with vanadium addition up to 7 at\% were investigated by the Mössbauer spectroscopy and magnetic methods. The outcomes evidence alterations in grain structure, although the main effect is related to the changes in intergranular phase. This induces diminution of mean hyperfine field, saturation induction and Curie temperature as well as the increase in coercivity.
\end{abstract}

PACS numbers: 75.50.--y, 76.80.+y

\section{The subject and methods of the study}

Nanocrystalline FINEMET $\Theta$ alloys obtained by controlled annealing of the amorphous precursor and composed of fine grains enclosed in an amorphous matrix are known as excellent soft magnetic materials $[1,2]$. In order to improve the magnetic properties, various modifications of chemical composition have been proposed for the last decade [3-6]. In this paper, the substitution of iron atoms by vanadium ones is considered. Previous X-ray diffraction (XRD) and transmission electron microscopy (TEM) studies indicate changes of local structure due to vanadium addition as well as preservation of the nanocrystalline structure with grains sizes of about $15 \mathrm{~nm}$ [7]. In this paper, the systematic Mössbauer study is presented, complemented with results of magnetic investigations.

The series of $\mathrm{Fe}_{73.5-x} \mathrm{~V}_{x} \mathrm{Cu}_{1} \mathrm{Nb}_{3} \mathrm{Si}_{13.5} \mathrm{~B}_{9}$ ribbons $(x=1,3,5,7)$ was manufactured by rapid quenching from the melt. Subsequent annealing for $1 \mathrm{~h}$ at 
$540^{\circ} \mathrm{C}$ under vacuum caused partial crystallization resulted in arising of the finegrain structure. The Mössbauer spectroscopy investigations were performed in the temperature range $300 \div 570 \mathrm{~K}$ with the use of ${ }^{57} \mathrm{Co}(\mathrm{Rh})$ source of $\gamma$ radiation, placed at a vibrator working in a constant acceleration mode, as well as a proportional detector and a vacuum furnace. Magnetic properties were determined with the use of a fluxmeter (for saturation induction and coercivity) and small angle magnetization rotation method (for magnetostriction).

\section{Results and discussion}

The Mössbauer spectra of the as-quenched ribbons take on a smooth shape which verifies the amorphous structure of these alloys. A positive correlation factor $a=150 \mathrm{~T} \mathrm{~s} / \mathrm{mm}$ between magnetic hyperfine field ( $\mathrm{HF}), B$, and isomer shift $\delta$ was employed in the numerical analysis of spectra, which is (approximately) consistent with the derived relationship between mean values of these parameters (Fig. 1a). The magnetic HF distributions show a bimodal character (Fig. 1b) with
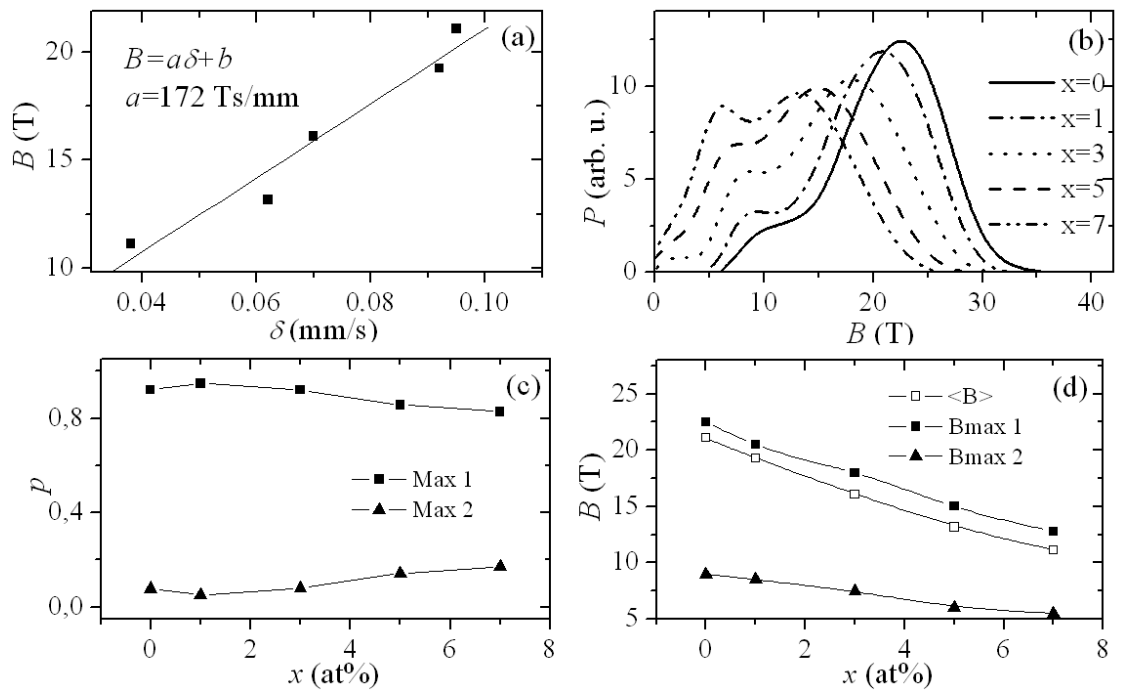

Fig. 1. Mean isomer shift versus magnetic HF (a), magnetic HF distribution (b), relative fraction $p$ of individual maxima in the distribution (c), and position of maxima at hyperfine field axis (d), derived for amorphous $\mathrm{Fe}_{73.5-x} \mathrm{~V}_{x} \mathrm{Cu}_{1} \mathrm{Nb}_{3} \mathrm{Si}_{13.5} \mathrm{~B}_{9}$ alloys.

growing low-field component when increasing vanadium concentration (Fig. 1c). In order to verify the real nature of the low-field component, the quadrupole splitting $\Delta$ was evaluated on the basis of spectra collected at elevated temperature, above the Curie point. The value $\Delta / 2=0.25 \mathrm{~mm} / \mathrm{s}$, which is much less than magnetic splitting $4 \div 6.5 \mathrm{~mm} / \mathrm{s}$, makes us sure that both components correspond to different local environments of iron atoms in the amorphous structure. Mean 
$\mathrm{HF}$ as well as positions of the maxima shift almost linearly with $x$ (Fig. 1d). This allows conclusion that the most crucial changes result from the diminution of iron. We have found that the Curie temperature $T_{\mathrm{c}}$ is also strongly influenced by vanadium addition. For example, its value has been reduced from about $600 \mathrm{~K}$ for pure FINEMET to $370 \mathrm{~K}$ for the alloy comprising $7 \mathrm{at} \%$ of vanadium. Similar value of the Curie temperature $T_{\mathrm{c}}=378 \mathrm{~K}$ was determined from magnetic measurements [7].

Concerning the nanocrystalline samples, the spectra comprise a component with continuous magnetic HF distribution - attributed to the amorphous remainder - and a discrete one, in form of a set of five Zeeman sextets, originating from crystalline grains (Fig. 2a-c). Besides, the existence of a paramagnetic component

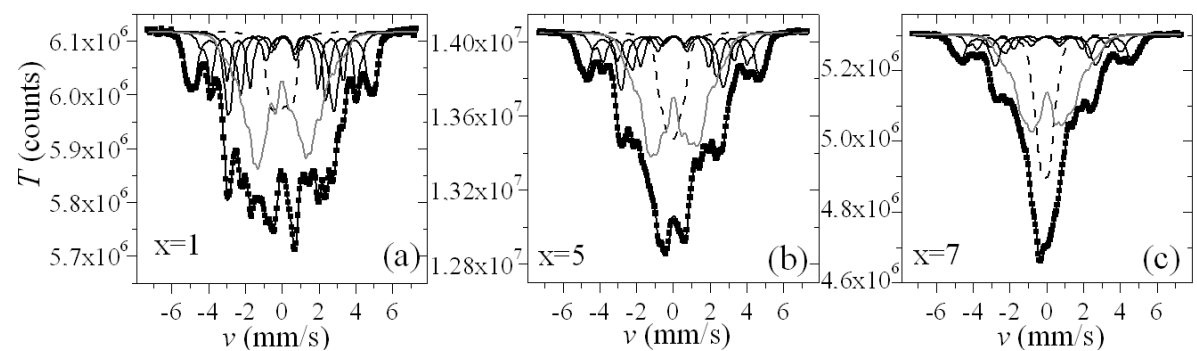

Fig. 2. Mössbauer spectra of $\mathrm{Fe}_{73.5-x} \mathrm{~V}_{x} \mathrm{Cu}_{1} \mathrm{Nb}_{3} \mathrm{Si}_{13.5} \mathrm{~B}$ alloys annealed for $1 \mathrm{~h}$ at $540^{\circ} \mathrm{C}$.

was stated, being characterized by a distribution of quadrupole splitting and, for this reason, attributed to iron-pure regions inside the amorphous matrix. The relative contribution of these areas grows with vanadium concentration and reaches $24 \%$ for $x=7$. Only slight but distinct changes in magnetic HF of individual sextets were found (Fig. 3a), which testifies alteration of grain structure, in accordance with previous XRD results indicating formation of $\mathrm{Fe}(\mathrm{V})_{3} \mathrm{Si}$ phase [7]. Significant decrease in mean magnetic HF is observed, in correlation with saturation induction (Fig. 3b).
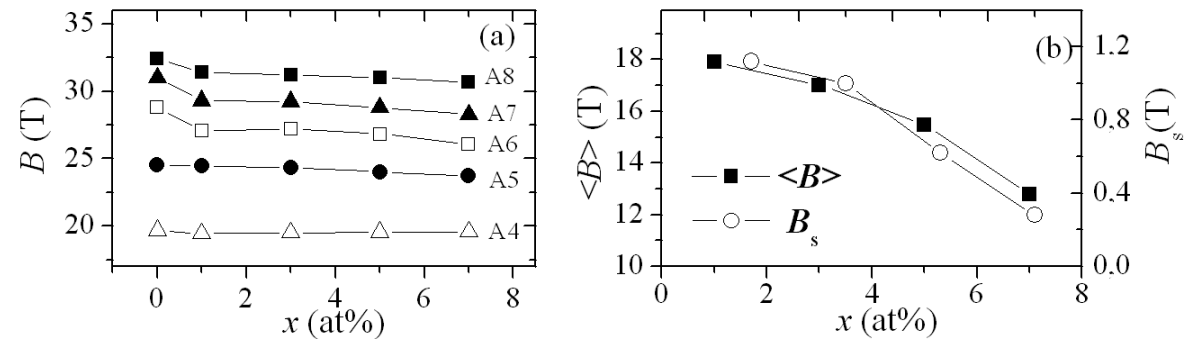

Fig. 3. Evolution of magnetic hyperfine field derived for individual sextets representing the crystalline phase (a), and mean magnetic hyperfine field as well as saturation induction $B_{\mathrm{s}}$ derived for $\mathrm{Fe}_{73.5-x} \mathrm{~V}_{x} \mathrm{Cu}_{1} \mathrm{Nb}_{3} \mathrm{Si}_{13.5} \mathrm{~B}$ alloys annealed for $1 \mathrm{~h}$ at $540^{\circ} \mathrm{C}$ (b). 

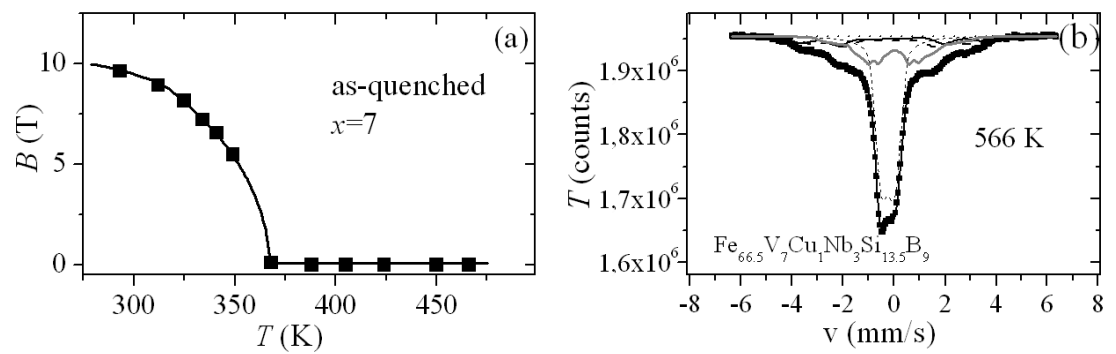

Fig. 4. Temperature evolution of magnetic hyperfine field of as-quenched alloy with 7 at\% of $\mathrm{V}$ (a), the spectrum of the annealed samples shows non-vanishing magnetic HF of amorphous matrix even above $T_{\mathrm{c}}^{\mathrm{am}}=360 \mathrm{~K}(\mathrm{~b})$.

Similarly as in amorphous samples (Fig. 4a), the considerable lowering of Curie temperature $T_{\mathrm{c}}^{\mathrm{am}}$ of the amorphous remainder in nanocrystalline alloys was found on the basis of the Mössbauer investigations, which evidences changes in chemical composition of the intergranular phase. Non-vanishing magnetic HF of some part of amorphous matrix (presumably close to grains surface) is observed even above $T_{\mathrm{c}}^{\mathrm{am}}$ (Fig. 4b). Saturation magnetostriction of as-quenched samples is a decreasing function of vanadium concentration and is reduced by $90 \%$ compared to pure FINEMET. A slight decrease in coercivity, compared with pure FINEMET, was also stated. For nanocrystalline alloys, the rapid increase in coercivity (by $40 \%$ ) is found.

\section{Conclusions}

Both Mössbauer and magnetic outcomes show the weakening of magnetic properties of FINEMET owing to vanadium addition. The evolution of hyperfine parameters of individual phases evidences that the main reason of the magnetic properties decay are strong changes in the structure of intergranular phase, which make exchange interactions between crystallites less efficient.

\section{References}

[1] Y. Yoshizawa, S. Oguma, K. Yamauchi, J. Appl. Phys. 64, 6044 (1988).

[2] G. Herzer, Phys. Scr. T 49, 307 (1993).

[3] T. Szumiata, B. Górka, A. Zorkovská, P. Sovák, J. Magn. Magn. Mater. 288, 37 (2005).

[4] J.M. Borrego, C.F. Conde, A. Conde, J.M. Grenèche, J Non-Cryst. Solids 287, 120 (2001).

[5] J. Füzer, P. Matta, P. Kollár, P. Sovák, M. Konč, J. Magn. Magn. Mater. 157/158, 205 (1996).

[6] T. Szumiata, M. Gawroński, K. Brzózka, B. Górka, P. Sovák, G. Pavlík, Nukleonika 52, S21 (2007).

[7] P. Sovák, G. Pavlík, V. Kolesár, K. Saksl, J. Füzer, J. Alloys Comp., in print. 